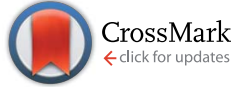

Cite this: RSC Adv., 2016, 6, 74742

Received 2nd June 2016 Accepted 30th June 2016

DOI: 10.1039/c6ra14345h

www.rsc.org/advances

\section{Recent studies on the decomposition and strategies of smoke and toxicity suppression for polyurethane based materials}

\author{
Xiu Liu, ab Jianwei Hao a and Sabyasachi Gaan*b
}

\begin{abstract}
The widespread application of polyurethane-based materials promotes its development and increases the requirement of flame retardancy and smoke toxicity properties. This review provides insight into recent studies related to thermal degradation, smoke and toxicity production for polyurethane-based materials. Factors influencing smoke production, smoke and toxicity suppression, mechanisms of polyurethane decomposition and its evaluation methods are summarized. Recent polyurethane smoke suppression strategies include the use of metal-based compounds (metal oxides, metal salts, metal-organic hybrids and metal hydroxides), melamine, carbon-based additives as well as other miscellaneous additives. The mechanism of action of these additives are also summarized in this review.
\end{abstract}

\section{Introduction}

The repeating unit in polyurethanes (PU) is the urethane bond (-NH-COO-) obtained from the reaction between an isocyanate $(-\mathrm{NH}=\mathrm{C}=\mathrm{O})$ and a polyol $(-\mathrm{OH})$. PU consists of alternating hard segments (HSs) and soft segments (SSs). HSs have high inter-chain interaction due to hydrogen bonding between the urethane groups. SSs, formed from linear long-chain diols or polyols, are flexible and weakly polar. ${ }^{1}$ PU plays an important role in the plastic application. In 2013, the global consumption of PU raw materials was above 21.7 million metric tons and the average annual growth rate is about $7 \%$. Global PU market demand is projected to increase to 24 million tons during the period of 2014 to $2020 .^{2}$

The PU family is an extremely large and complex set of polymers due to the existence of a variety of polyol and isocyanate raw materials. It is a very important polymeric material and finds application as elastomers, rigid and flexible foams, and adhesives. Thermoplastic polyurethanes (TPU) have been widely used in many industrial areas such as wires and cables, conveyor belts, automotive parts, electrical and electronic industries due to its excellent physical properties, abrasion resistances, chemical resistances, good adhesion to chemicals and self-lubrication properties. ${ }^{3,4}$ Rigid PU foam (RPUF) has wide applications in insulation, building construction,

\footnotetext{
${ }^{a}$ National Laboratory of Flame Retardant Materials, National Engineering and Technology Research Center of Flame Retardant Materials, School of Materials Science and Engineering, Beijing Institute of Technology, Beijing 100081, China ${ }^{b}$ Additives and Chemistry Group, Advanced Fibers, EMPA Swiss Federal Laboratories for Materials Science and Technology, Lerchenfeldstrasse 5, 9014 St. Gallen, Switzerland. E-mail: sabyasachi.gaan@empa.ch; Fax: +41 587657862; Tel: +41 587657611
}

chemical pipelines, space fillings and other applications. ${ }^{5}$ Flexible PU foams (FPUF) are usually used for cushioning material in many applications including those in furniture and automobiles. ${ }^{6}$ Other products of PU, such as protective and decorative coatings, synthetic fibres, synthetic leathers, sealants and textiles, find widespread application.

However, the high flammability of PU (LOI about 16-19\%) and its potential to produce large amounts of smoke and toxic gases during its burning has greatly limited its broad applications in some of the above mentioned fields. ${ }^{7-10}$ The fire and smoke hazards of PU causes great losses to society. A tragic PU mattress fire provoked death of 35 convicts in a prison (Unit I, Olmos, Penitentiary Service of Buenos Aires Province, Argentina), in 1990. Luis A. Ferrari et al. ${ }^{11}$ reported that HCN and CO generated by PU was the main cause of death. The Station nightclub fire on the 10th anniversary of the disaster, on February 20, 2003, smoke and toxic gas from the combustion of PU "egg crate" foam sound insulation on the club's walls caused 96 people to die and 200 more injured in less than 10 minutes, many catastrophically. ${ }^{12}$

Most fire deaths in buildings are due to toxic gases, oxygen deprivation and other effects that have been widely referred to as smoke inhalation instead of burns. ${ }^{\mathbf{1 3}, \mathbf{1 4}}$ The hazards of smoke in PU combustion can be attributed to three aspects. First, fire smoke of PU contains large amounts of toxic gases that easily cause poisoning and suffocation such as CO and HCN. Second, the high temperature smoke contains a lot of heat that can cause thermal damage to people and accelerate the spread of fire. Third, fire smoke can affect people's sight and reduce visibility, which may impact evacuation and rescue operations. ${ }^{15,16}$ Smoke density and toxicity have been considered as important factors in the evaluation of fire safety in some fire safety regulations, ${ }^{17-19}$ which further subdivides the hazards for 
people escaping from a fire into the effects of heat, asphyxia gases, irritant gases, and visual obscuration by smoke. The smoke suppression study of PU during combustion becomes crucial to satisfy the increasing safety requirements in practical usage. ${ }^{20}$

Approaches published in the literature for suppressing the smoke production of PU foams involve: (1) intrinsic structure modification of PU, the introduction of some low smoke production and char forming groups in the PU backbone; (2) the incorporation of smoke suppressants into the PU by simple mechanical mixing during the polymerization process; (3) coating on the surface of the PU samples with flame retardants or smoke suppressants.

The above mentioned strategies are described in detail in the subsequent sections. Based on these methods, some functional groups and elements that have smoke and toxicity suppression actions were employed to decrease the smoke production. The earlier reviews about polyurethane-based materials were focus on the thermal stability, combustion properties and flame retardancy as well as the reaction with other additives of polyurethane during the decomposition. ${ }^{21-24}$ Compared with the earlier reviews, this review is a summary of the past decade of research involving smoke and toxic gas production processes, with a focus on the smoke and toxic gas production, as well as suppression strategies, analyses of the smoke suppressants and their mechanisms used in PU manufacturing. It complements the earlier published reviews and provides a reference for the future study of PU smoke suppression and applications.

\section{Production of smoke and toxic gases from PU}

\subsection{Combustion and thermal degradation of PU}

The production of smoke depends on the structure and decomposition process of the polymer. PU materials are very combustible plastics with fast-spreading flames, high thermal emission and smoke production. ${ }^{21}$ In order to study the smoke production mechanism and determinate the optimum PU formulas to control the flammability and smoke production, it is essential to understand the decomposition process of PU. The thermal decomposition of $\mathrm{PU}$ is a complex heterogeneous process and consists of several partial decomposition reactions.

Some studies on the combustion and thermal degradation of different kinds of PU are listed in Table 1. From the already published literature ${ }^{25-41}$ on the thermogravimetric analysis of PU materials, thermal degradation usually occurs in two or three steps. The first mass loss peak is observed at about 200$350{ }^{\circ} \mathrm{C}$, and the second and third at about $350-600{ }^{\circ} \mathrm{C}$. The temperature and stages of thermal degradation not only depended on the chemical structure of the polyol and isocyanate components of the PU, but also on the test conditions, such as combustion atmosphere, temperature and heating rate. The thermal dissociation temperatures associated with various linages of PU are listed in Table 2. In general, the first step is attributed to degradation of hard segments: main polymer chain break up to isocyanates, alcohols, primary or secondary amines, olefins and carbon dioxide gasses. The second and third steps are ascribed to the decomposition of soft segments and fragments formed in the first steps to smaller molecules such as carbon dioxide, amine and water. ${ }^{21}$ Soft segments with weak structures, such as linear long-chains, and low bond energy will lower the decomposition temperature and increase the rupture rate of the second and third stages.

Combustion and pyrolysis mechanisms and smoke released from PU polymers have been studied using a variety of analytical tools such as thermogravimetric analysis (TGA), differential thermal analysis (DTA) and differential scanning calorimetry (DSC). Analysis methods including thermogravimetric analysismass spectrometry (TG-MS), ${ }^{\mathbf{4 2}}$ thermogravimetric analysis coupled with Fourier transformed infrared spectroscopy (TGFTIR), ${ }^{30}$ gas chromatography-mass spectrometry (GC-MS), ${ }^{43}$ high performance liquid chromatography analysis with fluorescence detection (HPLC-FD), ${ }^{44}$ laser pyrolysis and time-offlight mass spectrometry ${ }^{45}$ and synchrotron radiation vacuum ultraviolet photoionization mass spectrometry (SVUV-PIMS) ${ }^{\mathbf{4 6}}$ are specifically used to characterize the gas phase and condensed phase products formed from the combustion and pyrolysis of PU.

Various kinetic models related to conversion, temperature and other parameters have been built to study the combustion and thermal degradation of PU. Researchers ${ }^{25}$ have listed numerous kinetic models from various studies in the literature, most of them are two or three step consecutive reactions. It is worth noting that some studies ${ }^{47}$ used genetic algorithms and thermogravimetry to determine the kinetics of decomposition of PU foam in smouldering combustion. It is found that a fivestep mechanism and calculated kinetic parameters work well for the prediction of thermogravimetric data at different heating rates and gas atmospheres. A similar study ${ }^{6}$ suggested that each peak is the mass loss of a corresponding solid species by competing pyrolysis and oxidation pathways, so the five-step mechanism is composed of two foam pyrolyses, two foam oxidations and one char oxidation.

\subsection{Smoke and toxicity production from $\mathrm{PU}$}

Smoke is defined by ASTM E 176 as "the airborne solid and liquid particulates and gases evolved when a material undergoes pyrolysis or combustion”. PU produces large amounts of smoke and toxic gases during combustion. Smoke generation starts from the thermal decomposition in the condensed phase, breaks through the carbon layer, and then grows into smoke particles in the gas phase (Fig. 1). The quantity of smoke produced from PU remains sharply higher in the first $10 \mathrm{~min}$ after a fire starts. The formation of various kinds of fragments in the smoke mainly depends on the structure and composition of the PU. The toxicity of PU decomposition and combustion products have been reported $^{22,48,49}$ and some common products reported in the literature are listed in Table 3. PU is highly flammable and rapidly releases a lot of smoke in the first few minutes of the start of the fire. ${ }^{50}$

Smoke thus produced not only contains non-toxic products, such as carbon dioxide and nitrogen, but also some 
Table 1 Some studies on the combustion of different kinds of PU

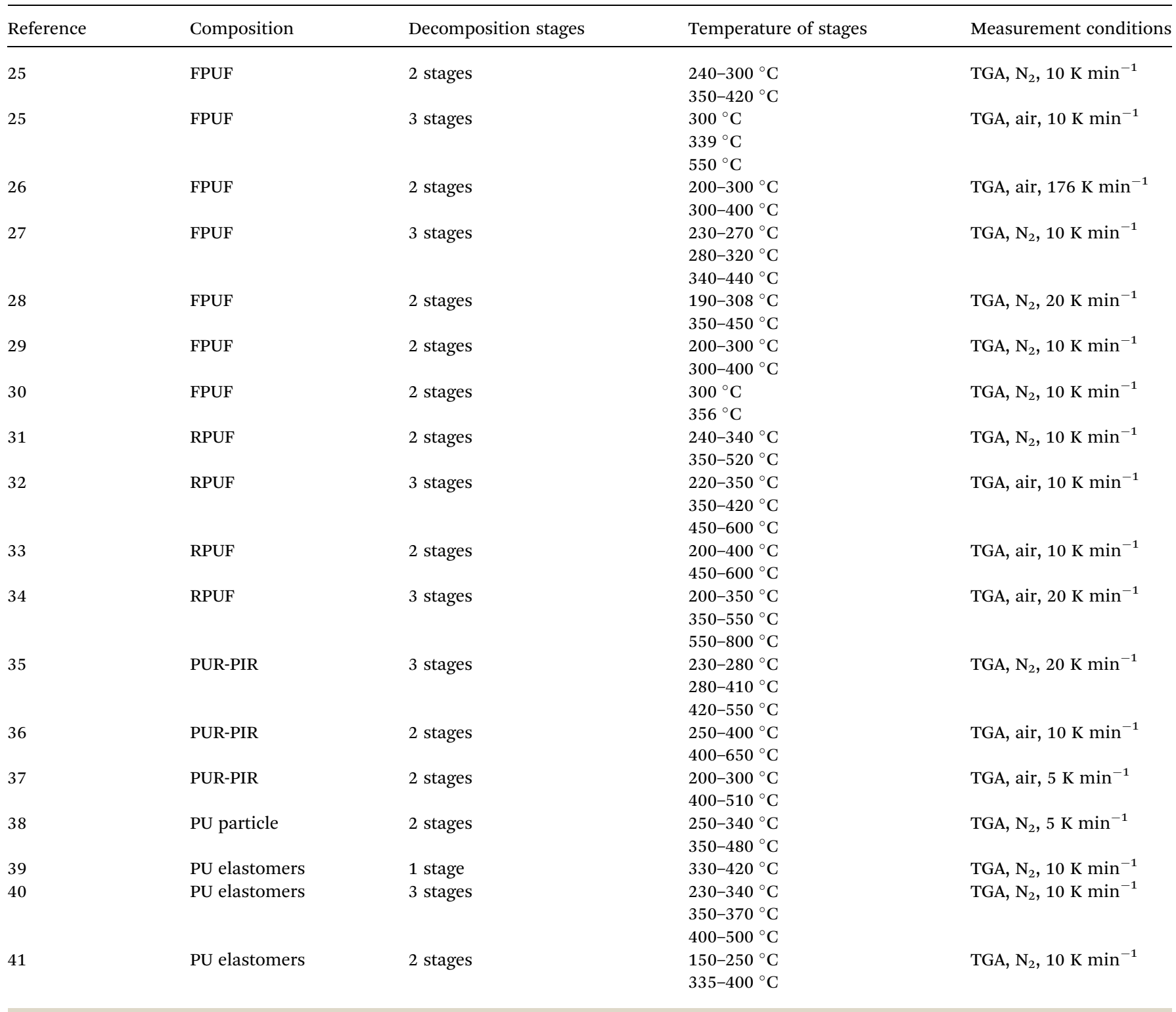

Table 2 Thermal dissociation temperatures of specific bonds found in PUs

\begin{tabular}{lll}
\hline & \multicolumn{2}{l}{ Onset of dissociation } \\
\cline { 2 - 3 } Linkage & ${ }^{\circ} \mathrm{C}$ & ${ }^{\circ} \mathrm{F}$ \\
\hline Carbodiimide & $250-280$ & $482-536$ \\
Isocyanurate & $270-300$ & $518-572$ \\
Aliphatic allophanate & $85-105$ & $185-220$ \\
Aromatic allophanate & $100-120$ & $212-250$ \\
Aliphatic biuret & $100-110$ & $212-230$ \\
Aromatic biuret & $115-125$ & $240-260$ \\
Aliphatic urea & $140-180$ & $285-355$ \\
Aromatic urea & $160-200$ & $320-355$ \\
Aliphatic urethane & $160-180$ & $320-355$ \\
Aromatic urethane & $180-200$ & $355-395$ \\
Disubstituted urea & $235-250$ & $455-480$
\end{tabular}

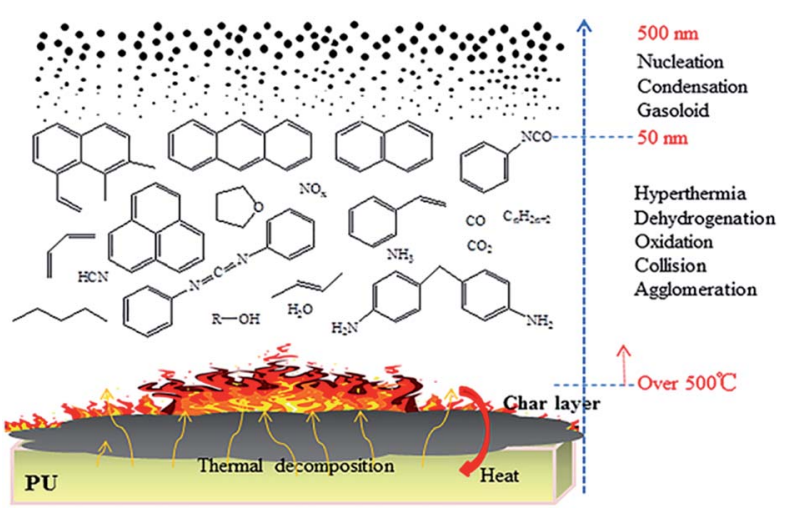

Fig. 1 Smoke generation model of PU in combustion. 
Table 3 Decomposition products of PU by mass spectrometry

\begin{tabular}{llll}
\hline Number & $\begin{array}{l}\text { Decomposition } \\
\text { product }\end{array}$ & Number & $\begin{array}{l}\text { Decomposition } \\
\text { product }\end{array}$ \\
\hline 1 & Nitrogen & 20 & Isoquinoline \\
2 & Carbon dioxide & 21 & Naphthalene \\
3 & Carbon monoxide & 22 & Methyl cyanobenzene \\
4 & Ethylene & 23 & Pyridine \\
5 & Ethane & 24 & Toluene \\
6 & Water & 25 & Methyl pyridine \\
7 & Propane & 26 & Cyclooctatetrene \\
8 & Hydrogen cyanide & 27 & Vinyl pyridine \\
9 & Butyne or butadiene & 28 & Benzonitrile \\
10 & Acetonitrile & 29 & Indene \\
11 & Acrylonitrile & 30 & 2-Methyl-1,3-dioxolane \\
12 & Propionitrile & 31 & 2-Ethoxyethanol \\
13 & Methyl acrylonitrile & 32 & 1,2-Diethoxyethane \\
14 & Benzene & 33 & 2-(2-Methoxyethoxy)ethanol \\
15 & Vinyl acetonitrile & 34 & 1,1-Oxybis(2-ethoxyethane) \\
16 & Pyrrole & 35 & Methyl anilines \\
17 & Nitrogen oxide & 36 & Amide \\
18 & Acetaldehyde & 37 & Acetone \\
19 & Acetamide & 38 & Pyridine, 2-methyl
\end{tabular}

significantly toxic components such as carbon monoxide (CO), hydrogen cyanide ( $\mathrm{HCN}), \mathrm{NH}_{3}$ and $\mathrm{NO}_{x} \cdot{ }^{51}$ Production of $\mathrm{CO}$, $\mathrm{HCN}$ and $\mathrm{CO}_{2}$ increase while $\mathrm{O}_{2}$ decreases rapidly just prior to, and shortly after, flame ignition of flexible PU foam, as determined according to NES-713. ${ }^{52}$ NES-713 offers the concentration of 14 different toxic gasses expressed as a factor of the concentration fatal to humans in a 30 min exposure time $\left(C_{\mathrm{f}}\right)$ (Table 4)..$^{53}$ The lower the value of $C_{\mathrm{f}}$, the more poisonous it is. Among the gases from $\mathrm{PU}$ decomposition, $\mathrm{HCN}$ and $\mathrm{NO}_{x}$ are highly toxic decomposition gases. In addition, the isocyanate released from the depolymerisation of $\mathrm{PU}$, which can cause lung injury, is also a toxic product in the combustion. ${ }^{54,55} \mathrm{CO}$ is one of the most toxic components of gases formed in fire because it prevents oxygen transport in living beings by the formation of

Table 4 The toxic concentration fatal to humans at 30 min exposure with NES-713 (ref. 53)

\begin{tabular}{ll}
\hline Gas & $C_{\mathrm{f}}^{a}(\mathrm{ppm})$ \\
\hline Carbon dioxide $\left(\mathrm{CO}_{2}\right)$ & $1 \times 10^{5}$ \\
Carbon monoxide $(\mathrm{CO})$ & $4 \times 10^{3}$ \\
Hydrogen sulphide $\left(\mathrm{H}_{2} \mathrm{~S}\right)$ & 750 \\
Ammonia $\left(\mathrm{NH}_{3}\right)$ & 550 \\
Formaldehyde $(\mathrm{HCHO})$ & 500 \\
Hydrogen chloride $(\mathrm{HCl})$ & 500 \\
Sulphur dioxide $\left(\mathrm{SO}_{2}\right)$ & 400 \\
Acrylonitrile $\left(\mathrm{CH}_{2} \mathrm{CHCN}\right)$ & 400 \\
Nitrogen oxides $\left(\mathrm{NO}_{x}\right)$ & 250 \\
Phenol $\left(\mathrm{C}_{6} \mathrm{H}_{5} \mathrm{OH}\right)$ & 250 \\
Hydrogen cyanide $(\mathrm{HCN})$ & 150 \\
Hydrogen bromide $(\mathrm{HBr})$ & 150 \\
Hydrogen fluoride $(\mathrm{HF})$ & 100 \\
Phosgene $\left(\mathrm{COCl}_{2}\right)$ & 25
\end{tabular}

${ }^{a} C_{\mathrm{f}}$ is the concentration of the gas considered fatal to man for a $30 \mathrm{~min}$ exposure time. carboxyhaemoglobin. $\mathrm{HCN}$ is more important because of its higher toxicity than $\mathrm{CO}$ and can prevent uptake of oxygen by the cells. The amount of HCN generated in a fire depends on a number of factors including the amount of cyanide in the burning material, the chemical composition of the $\mathrm{PU}$, the oxygen content in the room and the temperature of the fire. ${ }^{56}$ HCN production of $\mathrm{PU}$ in combustion is usually higher than the two other nitrogen-containing polymers, nylon and polyacrylonitrile, due to the large content of isocyanate in the PU polymer chain. ${ }^{57}$ Purser $^{58}$ has reported that yields of HCN show similar relationships to equivalence ratios as those for $\mathrm{CO}$. He also found that close correlations existed between the conversion rate of $\mathrm{N}$ to $\mathrm{HCN}$ and the conversion rate of $\mathrm{C}$ to $\mathrm{CO}$ for each investigated material. Woolley et al..$^{59}$ detected mostly $\mathrm{HCN}$ from the combustion of PU foam under air or nitrogen at $700-1000{ }^{\circ} \mathrm{C}$. From $300{ }^{\circ} \mathrm{C}$ to $800{ }^{\circ} \mathrm{C}$, intoxication was mainly caused by $\mathrm{CO}$, although some $\mathrm{HCN}$ was produced. Above $800{ }^{\circ} \mathrm{C}, \mathrm{HCN}$ became the dominant toxicant during the combustion of FPUF. ${ }^{60}$

\subsection{Evaluation of the smoke and toxicity from PU}

Evaluation of the toxicity fire hazard is based on two criteria. Firstly, the time concentration profiles for major products, which depends on the fire growth and yields of toxic products. Even though non-toxic $\mathrm{CO}_{2}$ can lead to death in high concentrations, the time concentration profiles are important. Secondly, the toxicity of the products that are based on the estimates of doses that impair escape efficiency cause incapacitation or lead to death. Toxicity calculation by volatile products is one of the methods used to estimate the toxicity of PU decomposition; the other is toxicity tests with various animals. ${ }^{61,62}$ In research, some analytical techniques are commonly used to quantitatively and qualitatively assess the smoke and toxicity of the gasses evolved during PU decomposition. Fire tests on a conventional cone calorimeter provide information regarding smoke production. By using an FTIR attachment (hyphenated accessory), one can also monitor production of specific gasses such as $\mathrm{HCN}, \mathrm{CO}$ and $\mathrm{CO}_{2} \cdot{ }^{63}$ The smoke density rating test estimates smoke production by the luminous flux of unit mass materials. ${ }^{64}$ Gas phase analysis using other hyphenated techniques, such as TG-MS, TG-FTIR and pyrolysis GC-MS mentioned earlier in Section 2.1, are also widely used for similar analyses.

The toxicants were predicted by Stec et al. ${ }^{65}$ according to the Purser's FED (Fractional Effective Dose) model in eqn (1). This model expresses the ratio of the concentration of each toxicant to its lethal concentration, and then multiplies the sum of this ratio by the hyperventilation factor. ${ }^{66}$ The higher the FED values, the greater the toxicity of the effluent is. Compared to several insulation materials (glass wool, stone wool, expanded polystyrene foam and phenolic foam), PU foam and polyisocyanurate (PIR) foam have higher FEDs in both wellventilated and under-ventilated flaming fire conditions. The results show that $8 \mathrm{~g}$ of PIR or $11 \mathrm{~g}$ of PUR foam burning in under-ventilated conditions would make $1 \mathrm{~m}^{3}$ of toxic air; or, 1 $\mathrm{kg}$ of such foam burning in under-ventilated conditions would provide lethal concentrations of toxicants in a $100 \mathrm{~m}^{3}$ room. 


$$
\begin{aligned}
\mathrm{FED}= & \left\{\frac{[\mathrm{CO}]}{\mathrm{LC}_{50, \mathrm{CO}}}+\frac{[\mathrm{HCN}]}{\mathrm{LC}_{50, \mathrm{HCN}}}+\frac{[\mathrm{HCl}]}{\mathrm{LC}_{50, \mathrm{HCl}}}+\ldots\right\} \times V_{\mathrm{CO}_{2}}+A \\
& +\frac{21-\left[\mathrm{O}_{2}\right]}{21-5.4} \quad V_{\mathrm{CO}_{2}}=1+\frac{\exp \left(0.14\left[\mathrm{CO}_{2}\right]\right)-1}{2}
\end{aligned}
$$

where $A$ is an acidosis factor equal to $\left[\mathrm{CO}_{2}\right] \times 0.05$ and $\mathrm{LC}_{50, \mathrm{X}}$ is the lethality for all gases obtained from rat exposure data (for $50 \%$ of the population over a $30 \mathrm{~min}$ exposure).

According to the NES-713 mentioned in Section 2.2, the test is used to estimate the toxicity of the products of combustion in terms of small molecular species that arise when a small sample of material is completely burnt in excess air under specified conditions. This test can provide the toxic load estimation for polymeric materials. In addition, some animal studies were also performed. Levin et al. ${ }^{67}$ exposed 344 male rats to gases produced from the thermal decomposition of PU and estimated the effluent toxicity. Different smoke concentrations from PU foams were presented to the animals to compare the toxicity of various compositions of $\mathrm{PU}$ foams.

\section{Factors influencing smoke production}

\subsection{Structure of PU}

The thermal stability and smoke production of PU mainly depends on its composition. Various PU compositions degrade at different temperatures due to the different decomposition temperatures of specific bonds in the polymer (Table 2). Some groups, such as the aromatic backbone, will improve the thermal stability of polymer and reduce smoke production. It is well known that the relationship between char formation and smoke production are competitive. For polymers that have a good char forming capacity, more fragments from combustion are kept in the condensed phase and less are released into the gas phase. Some entirely aromatic liquid-crystalline polyesters, $^{68}$ all aromatic poly (ether imide) $\mathrm{s}^{69}$ and poly (ether ketone) $\mathrm{s}^{70,71}$ present excellent thermal properties and undergo thermal degradation with formation of char as a consequence of the presence of aromatic entities in the main chain. The employment of these kinds of groups in the polyurethane structure can improve the thermal stability of polyurethane. In addition, some flame retardant elements, such as $\mathrm{P}$, can also be introduced in the backbone of the polymer to increase the thermal stability and char formation..$^{72,73}$

The functionality of the polyol and isocyanate are important factors determining the thermal degradation behaviour of PU. They can determine the crosslinking density of PU and char formation. ${ }^{74}$ Besides them, the introduction of the PIR structures, composed of a stable three-dimensional network structure, ${ }^{75,76}$ has a significant influence on their thermal degradation and smoke release. Similarly, carbodiimide groupcontaining urethane foams exposed to fire char and generate less smoke than conventional urethane foams. ${ }^{22,77}$

MDI-based PIR rigid urethane foams catalysed by 2,4,6-tris $N, N$-dimethylaminomethyl phenol show low flame spread and low smoke density in the ASTM E 84 fire test. ${ }^{78}$ The increase of isocyanate index in PU foams allows for a gradual increase in the initial degradation temperature. ${ }^{79}$ Due to the higher amount of TDI used for the synthesis of low density foams, it leads to an increase in the peak values of heat release rate and smoke production during the first stage of combustion. With the increase of isocyanate index from 150 to 250 , total smoke release of the PU-PIR system decreases from $560 \mathrm{~m}^{2} \mathrm{~m}^{-2}$ to 404 $\mathrm{m}^{2} \mathrm{~m}^{-2}$. Increased char residues in TGA, from $17.4 \%$ to $25.1 \%$, leads to a reduction in smoke release. Higher isocyanate indexes increase the amount of aromatic rings in the main chain and the degree of crosslinking, which facilitate char formation and keep more fragments in the condensed phase. ${ }^{74}$

Rosado et al. investigated the thermal degradation of $\mathrm{PU}$ foam with different structures. Compared to the PU with aliphatic polyester polyols, the PU with the aromatic polyester polyols has more thermal stability and higher char residue. PU with a higher average molecular mass (2000) polypropylene glycol has a stronger flame resistance and a higher char residue amount compared to the PU with lower molecular mass (200) polypropylene glycol. ${ }^{80}$

\subsection{Combustion conditions}

The composition of the gases produced during the thermal decomposition depends on the oxygen concentration, the temperature in the room and also on the material that is burned. It is reported in the literature that different combustion conditions produce different qualities and quantities of smoke. The irradiance level in the cone calorimeter exerts a strong influence on the decomposition rate of the PU molecular chain. Wang $\mathrm{J}$ et al. have investigated the combustion behaviour of FPUR at different heat fluxes. With increased heat fluxes, the peak heat release rate (PHRR), total heat release (THR), total smoke production (TSP) and the maximum concentration of $\mathrm{CO}, \mathrm{HCN}$ and $\mathrm{HCl}$ in fire effluents of flame retarded rigid PU foam increases from $31 \mathrm{~kW} \mathrm{~m}^{-2}, 8.0 \mathrm{MJ} \mathrm{m}^{-2}, 3.8 \mathrm{~m}^{2} \mathrm{~m}^{-2}, 192.7$ $\mu \mathrm{L} \mathrm{L}^{-1}, 42.7 \mu \mathrm{L} \mathrm{L}^{-1}$ and $77.4 \mu \mathrm{L} \mathrm{L}^{-1}$ to $260 \mathrm{~kW} \mathrm{~m}^{-2}, 39.7 \mathrm{MJ}$ $\mathrm{m}^{-2}, 13.8 \mathrm{~m}^{2} \mathrm{~m}^{-2}, 734.5 \mu \mathrm{L} \mathrm{L}^{-1}, 157.7 \mu \mathrm{L} \mathrm{L}^{-1}$ and $210.5 \mu \mathrm{L} \mathrm{L}^{-1}$, respectively (Table 5). ${ }^{81}$

$\mathrm{Xu}$ et al. have measured the gas components and other characteristics of PU foam under different heat fluxes, in a cone calorimeter. With increasing heat flux, both the production of $\mathrm{CO}$ and $\mathrm{CO}_{2}$ increases. ${ }^{82}$ Lucas et al. studied the combustion of polyether PU foam at different levels of irradiance in a cone calorimeter. Results show that the production of $\mathrm{CO}$ was decreased by $50 \%$ and the time of ignition was delayed by 80 seconds when the irradiance decreased from 50 to $10 \mathrm{~kW} \mathrm{~m}^{-2}$. The trend of nitrogen oxides production is similar to that of $\mathrm{CO}$ production. ${ }^{83}$ With the increase of irradiance level, the burning velocity is increased, so the production of $\mathrm{CO}$ is improved due to the lack of oxygen. ${ }^{84}$ In the study by Chow et al., $\mathrm{CO}$ and $\mathrm{CO}_{2}$ were measured and the peak FED (fractional effective dose) under different radiative heat fluxes were calculated. ${ }^{85}$ With the increase of heat from 20 to $65 \mathrm{~kW} \mathrm{~m}^{-2}$, the value of FED increased from $6 \times 10^{-4}$ to 0.05 . This means that the fire risks are significantly increased with a rise in heat flux. A fire condition that changes from well-ventilated to under-ventilated 
Table 5 The detailed data of rigid PU foams with different heat fluxes

\begin{tabular}{|c|c|c|c|c|c|c|c|}
\hline Sample & Heat fluxes $\left(\mathrm{kW} \mathrm{m}^{-2}\right)$ & PHRR $\left(\mathrm{kW} \mathrm{m}^{-2}\right)$ & THR $\left(\mathrm{MJ} \mathrm{m}^{-2}\right)$ & $\operatorname{TSP}\left(\mathrm{m}^{2} \mathrm{~m}^{-2}\right)$ & $\mathrm{CO}\left(\mu \mathrm{L} \mathrm{L}^{-1}\right)$ & $\mathrm{HCN}\left(\mu \mathrm{L} \mathrm{L}^{-1}\right)$ & $\operatorname{HCl}\left(\mu \mathrm{L} \mathrm{L}^{-1}\right)$ \\
\hline FPUR25 & 25 & 131 & 8.0 & 3.8 & 192.7 & 42.9 & 77.4 \\
\hline FPUR35 & 35 & 181 & 17.2 & 8.0 & 500.0 & 107.1 & 148.8 \\
\hline FPUR75 & 75 & 260 & 39.7 & 13.3 & 734.5 & 157.7 & 210.5 \\
\hline
\end{tabular}

is another reason behind the difference in smoke production. A PU based mattress burned with a steady flame both during the well ventilated and the vitiated tests. In these experiments, $\mathrm{HCN}, \mathrm{NO}$ and $\mathrm{NH}_{3}$ were also detected apart from $\mathrm{CO}_{2}$ and $\mathrm{CO}$. $\mathrm{HCN}$ was found under both well-ventilated and vitiated conditions, whereas NO was found only under well-ventilated conditions and $\mathrm{NH}_{3}$ was found only under vitiated conditions. ${ }^{86}$ The higher production of $\mathrm{HCN}$, together with $\mathrm{NH}_{3}$ production instead of NO at vitiated conditions, is typical for vitiated combustion of nitrogen-containing products. ${ }^{87}$

Levin et al. ${ }^{67}$ exposed 344 male rats to the thermal decomposition products from a PU foam. The decomposition products of the PU foam produced no animal deaths during exposure and caused post exposure deaths only in the non-flaming modes. Thus, it is clear from the above examples that various flame condition results in different levels of smoke production.

\subsection{Presence of flame retardants}

Flame retardants are the most important additives widely used in PU to reduce its flammability. Due to the different modes of action of such additives, they have an influence on the smoke and toxicity production of PU. Flame retardants, which are mainly active in the condensed phase, can reduce smoke release from PU. ${ }^{27,88,89}$ Duquesne et al. reported the study about APP in rigid PU. The emissions of $\mathrm{CO}$ and $\mathrm{CO}_{2}$ were significantly decreased, the volume of smoke production was reduced by $40 \%$ and the production of CO was decreased $80 \%$ at $40 \mathrm{wt} \%$ APP loading..$^{90}$ Some N-containing flame retardants also can decrease smoke release and will be discussed later in Section 4 .

However some other flame retardants that mainly act in the gas phase, such as liquid phosphate (DMMP) and phosphorushalogen compound TCPP, can significantly increase the smoke production of polymer. Active species, like $\mathrm{PO}^{*}$ and $\mathrm{Cl}^{*}$, released by phosphonate can interfere in the combustion process by recombining with $\mathrm{H}^{*}$ and $\mathrm{OH}^{*}$ to prevent their oxidation. ${ }^{29,91}$ They evolve abundant phosphorus oxides and degradation fragments that can lead to an increase in the smoke density and toxicity. ${ }^{\mathbf{9 2 , 9 3}}$ DMMP, and more recently phosphonamidates, when incorporated into PU have been shown to increase the CO yield. This is probably due to DMMP playing an important role in the gas phase. It is proposed that these additives generate $\mathrm{PO}_{2}$ and $\mathrm{PO}$ radicals at high temperatures that can then trap very active $\mathrm{OH}$ and other free radicals and hinder transformation of $\mathrm{CO}$ to $\mathrm{CO}_{2} \cdot{ }^{94} \mathrm{~A}$ series of phosphorus-containing flame retardants like DOPOphosphonamidates, TCPP and ExolitßOP 560 were used in a flexible $\mathrm{PU}$ foam. All of the $\mathrm{CO} / \mathrm{CO}_{2}$ ratios in the cone calorimeter experiments were increased. ${ }^{29}$ Compared to the blank, PU foam addition of TCPP increases the $\mathrm{CO} / \mathrm{CO}_{2}$ production about by 8-fold and the addition of DOPOphosphonamidates increases the $\mathrm{CO} / \mathrm{CO}_{2}$ production about 45 times. Similarly, as in the case of DMMP, the gas phase flame inhibition of active phosphorus or halogen species will lead to incomplete combustion and increase in the production of $\mathrm{CO} .^{29}$

Babrauskas et al. $^{95}$ exposed rats to the thermal decomposition products of fire-retardant PU foam containing phosphonates. Only the head of each animal was exposed for $30 \mathrm{~min}$ to avoid heating of the whole body, which resulted in the immediate death of the animal. The toxicity of the combustion products from the foam was mainly attributed to the formation of a bicyclic phosphate ester in the smoke. Some halogen flame retardants, such as brominated flame retardant, can increase the production of smoke. This also attributed to the gas phase activity of such kinds of flame retardants. It can generate low energy free-radical chain terminating agents that can cause a considerable increase in smoke and CO production. The generation of large amounts of hydrogen halide will further increase the toxicity and corrosiveness of the evolved gas. ${ }^{\mathbf{9 3 , 9 6}}$ Additionally, some nitrogen-phosphates can also increase smoke production. Chen et al. used melamine phosphate in flexible PU foams and cone calorimeter test results show that the TSP increased 2.2-3.5 times. It is proposed to play a role in the gas phase, on one hand, some of its pyrolysis products containing the active groups of $-\mathrm{OH}$ and $-\mathrm{NH}_{2}$ can react with isocyanates decomposed from PU. On the other hand, flame retardants produce phosphorus containing free radicals that could scavenge $\mathrm{H}^{*}$ and $\mathrm{OH}^{*}$ in the gas phase. The gas phase action is stronger than the condensed phase, so the smoke production was increased. ${ }^{97}$

\subsection{Density and size of samples}

The surface area and thickness of the specimen both have a large effect on the heat release rate. ${ }^{98}$ Urbas investigated the effect of irradiance level, flame and specimen thickness on the cone calorimeter test results. With an increase in the thickness of the samples, the THR and smoke production also increased. ${ }^{99}$ The density of the samples has a large influence on the intensity of combustion, ${ }^{\mathbf{1 0 0}}$ it is also a factor that affects smoke production.

Small and large-scale fire experiments were performed by Levin et al. to evaluate the toxicity of PU foams. In the smallscale experiments, mortality depended on the amount of material burned. The amount of material required to produce $50 \%$ mortality (LC50) was measured. LC50 for the PU foam was 
$6.6 \mathrm{~g}$, lower than that for nylon (7 g), acrylic (8 g), cotton (10 g), or wood $(11 \mathrm{~g}){ }^{67}$ Lefebvre et al. ${ }^{101}$ related this to the density effect in smoke production. Higher density means large amounts of quantity in a unit volume of material. This will increase the smoke production due to the lack of oxygen in a limited space around the material.

\section{Smoke and toxicity suppression mechanisms}

In order to get optimal smoke suppression effects, various additives are widely used in polymers. Metal compounds such as oxides, hydroxides, salts and organic derivatives play an important role as smoke suppressants. Transition metal elements such as $\mathrm{Zn}, \mathrm{Fe}, \mathrm{Cu}, \mathrm{Ni}, \mathrm{Mn}$, Ti and Mo have attracted a lot of attention due to their excellent smoke suppression and flame retardancy properties in polymers. It has been reported that a little addition of ferrite in a polymer can significantly increase its activation energy of decomposition. ${ }^{\mathbf{1 0 2}}$ In some studies, iron compounds were found to be very effective in the presence of a char-forming resin. In formulations containing ferrites, the char morphology was compact. ${ }^{\mathbf{1 0 3}}$ Ferrites are not only effective in halogen-containing compounds, ${ }^{\mathbf{1 0 4 , 1 0 5}}$ but also in the absence of halogen-containing compounds. ${ }^{103,106}$ Moroi et al. reported the effect of some transition metal ions on the thermal behaviour of PU materials. ${ }^{107}$ The studies revealed that the thermal degradation of PU was affected by the presence of metallic ions and that each ion has a specific influence on the decomposition process. ${ }^{108}$ Some metal compounds and their smoke suppression effects are listed in Table 6. Besides metal compounds, some nitrogen-containing compounds and other organic acids have also been employed as smoke suppressants in polymers. Various smoke suppressants for PU reported in the literature are elaborated upon in the following sections.

\subsection{Metal oxides}

A series of published literature indicate that HCN generation was reduced by $90 \%$ and the resultant toxicity of the combustion products was lowered by $50 \%$ when $0.1 \mathrm{wt} \%$ cuprous oxide $\left(\mathrm{Cu}_{2} \mathrm{O}\right)$ was incorporated in the PU foam. ${ }^{109-111}$ Reductive coupling reactions of $\mathrm{Cu}_{2} \mathrm{O}$ have been proposed by Lattimer et al. ${ }^{112} \mathrm{Cu}_{2} \mathrm{O}$ can retard smoke release by promoting the crosslinking of polymer chain segments via a reductive coupling mechanism. Due to the conversion of $\mathrm{Cu}$ from higher to lower valence, the decomposition fragments are connected together during this process (Scheme 1). When red phosphorus is used as a flame retardant for PU, it generates highly toxic phosphine through a reaction with water in the combustion process. A stabilizer, such as a metal oxide, successfully minimizes trace amounts of phosphine. Studies show that copper oxide, cadmium oxide or zinc oxide can efficiently transform phosphine into phosphoric acid, which is inactive in the condensed phase. ${ }^{113}$

Chen et al. ${ }^{\mathbf{1 1 4}}$ proposed that $\mathrm{FeOOH}$ has a certain smoke suppression effect in TPU composites during the smoke density test. When the loading of $\mathrm{FeOOH}$ is $3.75 \mathrm{wt} \%$, the highest

$$
\begin{aligned}
& \mathrm{R}+\mathrm{CuO} \rightarrow \mathrm{R}-\mathrm{Cu}^{1} \\
& \mathrm{RCu}^{1}+\mathrm{R}^{\prime}-\mathrm{Cl} \rightarrow\left[\mathrm{RR}^{\prime} \mathrm{Cu}^{111} \mathrm{Cl}\right] \\
& {\left[\mathrm{RR}^{\prime} \mathrm{Cu}^{111} \mathrm{Cl}\right] \rightarrow \mathrm{R}-\mathrm{R}^{\prime}+\mathrm{Cu}^{1} \mathrm{Cl}}
\end{aligned}
$$

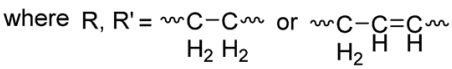

\begin{tabular}{|c|c|c|c|}
\hline Polymer & Reference & Metal compound loading & Relative difference in Smoke production \\
\hline FPUF & 111 & 0.1 wt $\%$ cuprous oxide $\left(\mathrm{Cu}_{2} \mathrm{O}\right)$ & $\begin{array}{l}\text { HCN generation was reduced by } 90 \% \text { and the resultant toxicity of } \\
\text { the combustion products was lowered by } 50 \%\end{array}$ \\
\hline TPU & 64 & $3.75 \mathrm{wt} \%$ ferrous & $\begin{array}{l}\text { The luminous flux of TPU-APP-ferrous }(89.5 \%) \\
\text { much higher than TPU-APP }(56 \%)\end{array}$ \\
\hline TPU & 114 & $3.75 \mathrm{wt} \% \mathrm{FeOOH}$ & Luminous flux increases from $6 \%$ to $32.7 \%$ \\
\hline FPUF & 122 & $15 \mathrm{wt} \% \mathrm{ZB}$ & $\begin{array}{l}\text { ZB can strengthen the dense structure of char; CO yield is } \\
\text { diminished greatly; the residual mass increase from } 0.9 \% \text { to } 6.8 \%\end{array}$ \\
\hline $\begin{array}{l}\text { FPUR } \\
\text { and RPUF }\end{array}$ & 120 & $50 \mathrm{wt} \% \mathrm{ZnCl}_{2}$ & CO production was decreased $50-54 \%$ compare with pure foam \\
\hline FPUR & 28 & $5.65 \mathrm{wt} \%$ titanate nanotubes & $\begin{array}{l}\text { Great reduction in peak SPR }(62.8 \%) \text {, TSR }(40.9 \%) \text { and peak CO } \\
\text { production }(63.5 \%)\end{array}$ \\
\hline TPU & 126 & $2 \mathrm{wt} \% \mathrm{CuCo}_{2} \mathrm{O}_{4}$ & Char residue increase from $3 \%$ to $9.9 \%$ and the $\mathrm{CO}$ release is reduced \\
\hline RPUF & 125 & $5 \mathrm{wt} \%$ ZHS & $\begin{array}{l}\text { The smoke production rate decrease about } 26.7 \% \text { with the addition of } \\
\text { ZHS in flame retardant RPUF with phosphate }\end{array}$ \\
\hline RPUF & 123 & $2 \mathrm{wt} \%$ zinc aluminate & $\begin{array}{l}\text { Zinc aluminate reduces the smoke density rating to } 43.9 \% \text { and prolongs } \\
\text { the release of isocyanate compound and hydrogen cyanide from FPUR }\end{array}$ \\
\hline FPUF & 132 & $15 \mathrm{wt} \%$ ferrocene & $\begin{array}{l}\text { High reduction in smoke production ( } 28 \% \text { reduction) as well } \\
\text { as CO yield ( } 68 \% \text { reduction) }\end{array}$ \\
\hline RPUF & 133 & $\begin{array}{l}\text { Ferrocene-modified copolymer } \\
\text { (1.54 wt } \% \text { Fe content })\end{array}$ & PHRR was reduced by $80 \%$, CO production was decreased $30 \%$ \\
\hline RPUF & 154 & 2 wt $\%$ boric silicon & Smoke production rate and CO release rate are decreased about $10 \%$ \\
\hline
\end{tabular}

Scheme 1 Reductive coupling reaction of $\mathrm{Cu}_{2} \mathrm{O}$ in PVC.

Table 6 Some metal compound smoke suppressants used in PU 
luminous flux is $32.7 \%$, which is even lower than that of TPU containing $20 \mathrm{wt} \%$ APP. FeOOH also has synergistic effects with APP and facilitates structure change of the char residue and reduces heat release and smoke generation. Jiao et $a .^{64}$ added ferrous powder in TPU and reported a synergistic effect with APP in TPU. The luminous flux of TPU-APP-ferrous is much higher than TPU-APP, about 34\% in the smoke density test.

It is not only because the ferrous powder can react with polyphosphoric acid formed from the decomposition of APP to form iron pyrophosphate, but ferrous can also change the expansion degree of the char residue. Both of these can keep more decomposition fragments in the condensed phase and reduces the smoke production. The reaction between metal oxides and phosphonate or phosphate is shown in Scheme 2 . Lin et al. investigated the flame retardancy and smoke suppression of thermoplastic PU filled with $\mathrm{MgO}, \mathrm{Fe}_{2} \mathrm{O}_{3}$ and ZnO. These metal oxides have synergistic effects with novel intumescent flame retardants. With $5 \mathrm{wt} \%$ loading of $\mathrm{MgO}$ and $\mathrm{Fe}_{2} \mathrm{O}_{3}$ in the intumescent systems, the TSP of foam was decreased in the cone test. ${ }^{115}$ In the system where $\mathrm{Fe}_{2} \mathrm{O}_{3}$ was used, the interaction between the phosphinate functionality and the inorganic oxide is believed to promote char formation. ${ }^{116}$ They also reported that the electric charge strength of the metal ions may be a major factor in determining whether a metal ion can catalyse the chain scission reactions. Apart from the acid behaviour, the surface of the metal oxide consists of oxide anions, or hydroxyl end groups, that provide active sites for anchoring other chemical species. As reported elsewhere, metal compounds may catalyse cross-linking activity. The metal cations facilitate the formation of the double bonds that undergo cross-linking, promoting additional carbonaceous char. ${ }^{103,117}$

In addition, other research proposed that the smoke suppression effect of ferrous powder in the polymer has two aspects. On one hand, it can promote soot particle oxidation to $\mathrm{CO}$ and $\mathrm{CO}_{2}$; on the other hand, it can accelerate the formation of a compact and stable char layer and prevent the release of smoke precursors, i.e., it keeps more degradation fractions in the condensed phase..$^{118,119}$

\subsection{Metal salts}

Several metal chlorides have been reported in PU applications. Zinc chloride can remarkably reduce gaseous products during the combustion of PU. One possible speculation is the difference in Lewis acidity of the metal chlorides. The stronger Lewis

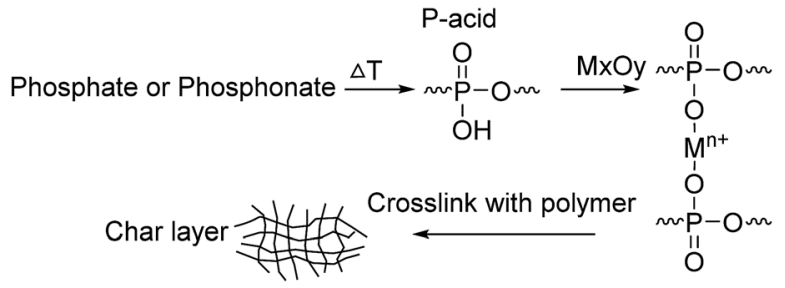

Scheme 2 Possible reaction mechanisms of char formation during combustion of the flame retardant epoxy system with ferrocene. acidity of zinc chloride over copper chloride enables fixation of more carbon in the polymer as a char. With a $50 \mathrm{wt} \%$ loading of $\mathrm{ZnCl}_{2}$, CO production was decreased $50-54 \%$ compared to the pure PU foam. ${ }^{120} \mathrm{ZnCl}_{2}$ has been suggested to act as in FriedelCrafts catalysis and promote the crosslinking of polymers in combustion. ${ }^{121}$ Some studies have reported that zinc borate (ZB) can greatly diminish the CO yield of FPUF, strengthen the density of the char and increase the char yield at high temperatures. The formation of toxic gases was investigated at different temperatures. $\mathrm{ZB}$ was not able to inhibit $\mathrm{CO}$ formation at $600{ }^{\circ} \mathrm{C}$ anymore because the pyrolysis ability was stronger at higher temperatures and flame retardants cannot stop the further decomposition of FPUF. ${ }^{122}$ Liu et al. ${ }^{123}$ used $\mathrm{ZnAl}_{2} \mathrm{O}_{4}, \mathrm{ZnFe}_{2} \mathrm{O}_{4}$ and $\mathrm{Zn}_{2} \mathrm{SiO}_{4}$ in rigid $\mathrm{PU}$ foam. The smoke density rating (SDR) and the specific extinction area were significantly decreased. Meanwhile, the release of isocyanate compounds and hydrogen cyanide from the foam was reduced and prolonged. $\mathrm{ZnFe}_{2} \mathrm{O}_{4}$ resulted in excellent char formation in the initial degradation stage and retained more phosphorus and decomposition fragments in the solid phase. On one hand, zinc salts delayed the release time of $\mathrm{PO}_{2}^{*}$. This was due to zinc salts promoting the crosslinking between phosphorus oxide and polymer degradation fragments, and inhibiting phosphorus oxide release into the gas phase. On the other hand, metal atoms in zinc salts may act as a Lewis acid and coordinate with the oxygen atom of the -NCO, causing the carbon of -NCO to be more electrophilic and more reactive with other molecular fragments.

The combined use of a phosphonate based flame retardant with zinc stannate (ZS) or zinc hydroxystannate (ZHS) can significantly reduce the smoke generation of flexible PU foams. ${ }^{124}$ ZS or ZHS has a significant impact on the smoke production of rigid PU foam. The phosphorus flame retardant increases the smoke production rate of the foam. PU foam with the combination of ZS exhibits a similar level of smoke production as pristine rigid PU foam. ${ }^{\mathbf{1 2 5}}$ Spinel copper cobalate $\left(\mathrm{CuCo}_{2} \mathrm{O}_{4}\right)$ is also used in PU to reduce the release of smoke and toxic gas. Shi et al. ${ }^{\mathbf{1 2 6}}$ added $\mathrm{CuCo}_{2} \mathrm{O}_{4}$ in TPU and the char residue increased from $3 \%$ to $9.9 \%$ at $2 \mathrm{wt} \%$ loading. This may be attributed to the fact that $\mathrm{CuCo}_{2} \mathrm{O}_{4}$ can change the decomposition pathway and transfer $\mathrm{CO}$ into $\mathrm{CO}_{2}$ during combustion. On the other hand, because of the synergistic effect between $\mathrm{CuCo}_{2} \mathrm{O}_{4}$ and graphitic carbon nitride, $\mathrm{NO}$ and $\mathrm{CO}_{2}$ (or $\mathrm{CO}$ ) are formed instead of the - NCO group at temperatures ranging 320-350 ${ }^{\circ} \mathrm{C}$. Meanwhile, $\mathrm{CuCo}_{2} \mathrm{O}_{4}$ can catalyse the further reaction between $\mathrm{NO}$ and $\mathrm{CO}$ to produce the $\mathrm{N}_{2}$ and $\mathrm{CO}_{2}$, thus decreasing the release of toxic gases.

\subsection{Metal organic compounds}

Synthesis and application of ferrocene and its derivatives in different polymers have been published and they have a significant effect on the thermal degradation of polymer, promote fire extinction and suppresses smoke production by accelerating char formation. ${ }^{\mathbf{1 2 7 - 1 2 9}}$ These compounds have good compatibility with polymers due to the presence of organic groups. Thermal decomposition kinetics of ferrocene-modified poly(epichlorohydrin-co-2-(methoxymethyl) oxirane)-based PU 
networks were investigated by TGA. Results from the Vyazovkin method showed that ferrocene increased the activation energies of polymer from $220 \mathrm{~kJ} \mathrm{~mol}^{-1}$ to $240 \mathrm{~kJ} \mathrm{~mol}^{-1} \cdot{ }^{130}$ Kishore investigated the fire retardancy of ferrocene containing polyphosphate esters. The incorporation of ferrocene improved the thermal stability of polymer and increased the char residue amount, which facilitated smoke suppression effects. ${ }^{\mathbf{1 3 1}}$ Large amounts of ferrocene ( $15 \mathrm{wt} \%$ ) as an additive shows a higher reduction in smoke production (28\% reduction) as well as CO yields (68\% reduction). ${ }^{132}$ Ferrocene-modified block copolyurethanes showed a 40-80\% reduction in the PHRR compared to an unmodified PU. Ferrocene in the backbone may be less volatile than ferrocene as an additive, and thus, less available for vapour phase reactions leading to a reduction in smoke and CO. But, it may be more available for solid phase reactions leading to enhanced char formation. ${ }^{\mathbf{1 3 3}}$

With the addition of $3 \mathrm{wt} \%$ PFAM (Scheme 3), the char shows a more compact and dense char layer compared to the virgin polymer, which provides a good barrier to inhibit the transmission of heat flow and smoke production when exposed to flame or heat sources. ${ }^{\mathbf{1 3 4}}$ This was attributed to possible synergy of ferrocene with phosphorus. Ferrocene can crosslink with the phosphoric acid and improve char formation. ${ }^{135}$ New 4,4'dihydroxysaltrien metal complexes $\left(\mathrm{MOHSal}_{2}\right.$ trien, where $\mathbf{M}=$ $\mathrm{Zn}$ or $\mathrm{Ni}$ ) were synthesized and used for the synthesis of metalcontaining polyurethane-urea and copolyurethane-urea. Among all metal-containing polyurethane ureas, $\mathrm{NiOHSal}_{2}$ trien-MDI is the most thermally stable polymer with the highest char yield of $55 \%$ at $600{ }^{\circ} \mathrm{C}$, which can keep more decomposition fragments in the solid phase. ${ }^{136}$

Some metal compounds can form Lewis acid sites, especially the transition metal halides, and can enhance char-forming reactions. ${ }^{137}$ As is well known, Lewis acids are able to accept an electron pair and create a coordinate bond. Polymers with strongly electronegative groups can coordinate Lewis acids and change the PU degradation mechanism. ${ }^{138}$ Usually, dehydrogenation of the polymer occurs and these unsaturation sites then lead to crosslinking and eventual graphitisation. These inhibit the release of decomposition fragments, which results in smoke and toxicity suppression.

\subsection{Metal hydroxides}

Aluminium trihydrate (ATH) or magnesium hydroxides (MH) are very widely used as flame retardants and smoke suppressants. ${ }^{139}$ They are cheap, safe and easily incorporated in many polymers and produces non-toxic fumes. Due to the high specific surface area of the oxide layer, they can absorb smoke and other toxic or decomposed gaseous products during combustion. On the other

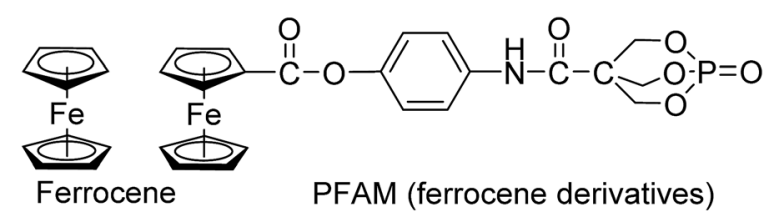

Scheme 3 Ferrocene and its derivatives. hand, the endothermic decomposition of ATH and $\mathrm{MH}$ releases large amounts of water vapour that can dilute the combustible gases from the burning polymer. Meanwhile, ATH and $\mathrm{MH}$ form an insulating barrier on the surface that can also inhibit the release of smoke. ${ }^{\mathbf{1 4 0 , 1 4 1}}$ ATH could effectively induce "villi" like particle generation on the surface and make the char layer more compact and dense. ${ }^{142}$

Liu et al. added $5 \mathrm{wt} \%$ ATH in PUR-PIR with $10 \mathrm{wt} \%$ DMMP. The total smoke release, $\mathrm{CO}$ emissions and $\mathrm{CO}_{2}$ emissions changed from 738.47 to $248.91 \mathrm{~m}^{2} \mathrm{~m}^{-2}$, from 0.206 to $0.008 \mathrm{~kg}$ $\mathrm{kg}^{-1}$ and from 3.218 to $0.121 \mathrm{~kg} \mathrm{~kg}^{-1}$, respectively. ${ }^{143}$ The effectiveness of ATH as a flame retardant additive depends primarily on its endothermic decomposition, which withdraws heat from the substrate and retards the rate of flame propagation. When ATH (with $40 \mathrm{wt} \%$ loading of ATH) with a specific surface area (according to BET of $4 \mathrm{~m}^{2} \mathrm{~g}^{-1}$ ) is used in the TPU, the smoke density of TPU is reduced by $43 \%{ }^{\mathbf{1 4 4}}$ The smoke density rating is reduced from $62 \%$ to $30 \%$ when $20 \mathrm{wt} \%$ ATH is filled in rigid PU foam. ${ }^{145}$

However, large loadings of these additives in the polymers destroy the physical and mechanical properties of the composites. This is possibly due to insufficient interactions between polymer and filler. So, some researchers have deposited $\mathrm{MH}$ on the surface of FPUF via the Layer-By-Layer assembly technique. When $10.3 \mathrm{wt} \% \mathrm{MH}$ was coated on the surface of FPUF, the smoke density decreased by $31.2 \%$. During the decomposition of $\mathrm{MH}$-coated FPUF, the active $\mathrm{MgO}$ formed from $\mathrm{MH}$ thermal decomposition promoted the FPUF carbonization and reduced the release of hydrocarbons and benzene. The smoke and soot particles were reduced by $\mathrm{MgO}$ sorption. ${ }^{\mathbf{1 4 6}}$

\subsection{Melamine and its derivatives}

More attention has been paid to the development of halogenfree FR additives recently. They are mainly based on phosphorus and nitrogen-based materials that form a char layer and also reduces the evolution of toxic smoke. Their main advantages are low toxicity, a solid state, and in the event of fire, absence of toxic gases and low evolution of smoke. The most important organic nitrogen compounds used as flame retardant additives are melamine and its derivatives, such as melamine oxalate, melamine phosphate, melamine phthalate and melamine cyanurate (MC). ${ }^{147}$

During heating, melamine is known to undergo progressive endothermic condensation with the release of ammonia, which is a flame diluent, and forms products such as melam, melem and melon. These products form the char layer and are more thermally stable than melamine (melam $\sim 350{ }^{\circ} \mathrm{C}$, melem $\sim 450{ }^{\circ} \mathrm{C}$ and melon $\left.\sim 600{ }^{\circ} \mathrm{C}\right) .{ }^{\mathbf{1 4 8 , 1 4 9}}$ At high temperatures melem and melon are formed. Then, graphitic carbon nitride, $\mathrm{g}-\mathrm{C}_{3} \mathrm{~N}_{4}$, is produced under further heating (Scheme 4).

So, the flame retardancy of MC-filled PUF is due to the endothermic decomposition of MC that leads to the evolution of ammonia (non-combustible gas) and the formation of condensation products such as melam, melem and melom, which constitute the char layer. ${ }^{\mathbf{1 5 0 , 1 5 1}}$ Due to the dilution effect 

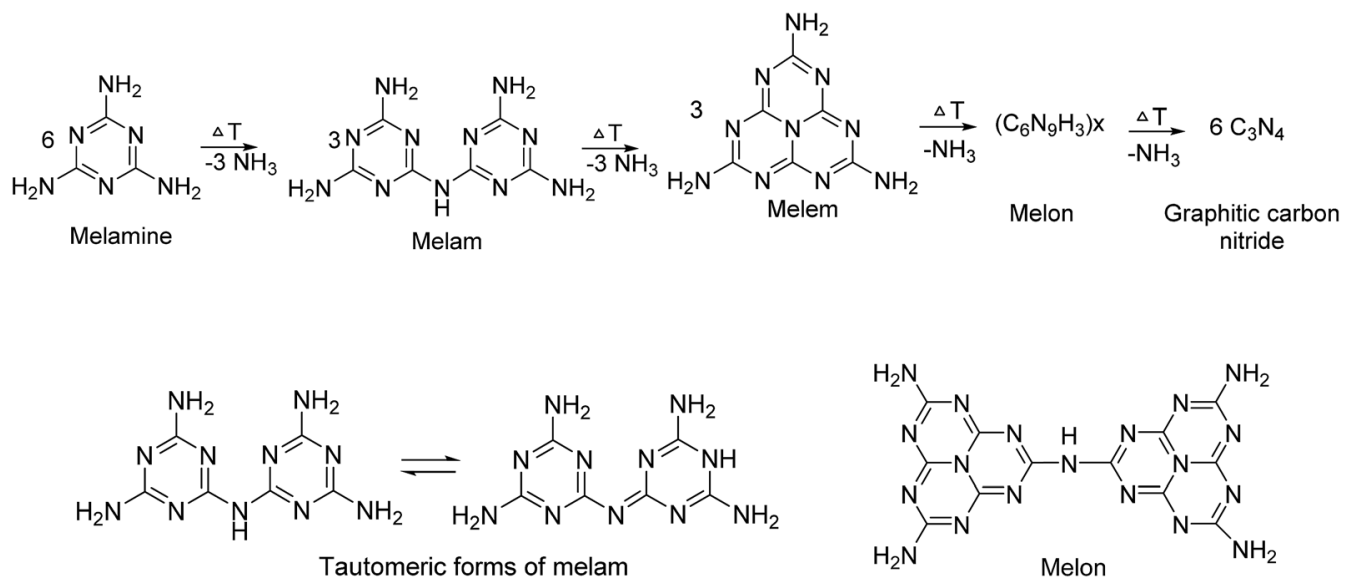

Scheme 4 Thermal decomposition of melamine and the formation of graphitic carbon nitride.

in the gas phase and char formation in the condensed phase of melamine, it has a smoke suppression effect in PU.

It has been reported that melamine is very effective in suppressing smoke and CO production from PU foam during the initial stage of combustion. With increasing melamine content to $60 \mathrm{wt} \%$ in flexible PU foam, the total smoke release was reduced from 80 to $8 \mathrm{~m}^{2} \mathrm{~m}^{-2}$ and $\mathrm{CO}$ production was decreased about $50 \%{ }^{149}$ This was due to the chemical interaction between melamine and the evolved isocyanate fraction released from the decomposition of PU foam. This interaction reduces the amount of toluene diisocyanate (TDI). With the addition of 9.8 wt $\%$ melamine, the amount of TDI released was reduced about $83 \%$ in the gas phase during decomposition. According to the report of Oertel et al., ${ }^{152}$ the amino group is known to be approximately three times more reactive than the hydroxyl groups of the polyols. At higher temperatures, the $-\mathrm{NH}_{2}$ group of melamine is known to be very reactive towards isocyanate (-NCO) groups. ${ }^{152,153}$ So the reaction in Scheme 5 would be expected to occur when the temperature is over $250{ }^{\circ} \mathrm{C}$. This reaction would reduce the amount of aromatic smoke precursor volatilization, thus reducing the smoke released. Additionally, this kind of structure would further degrade to char, which can protect the polymer underneath. ${ }^{155}$

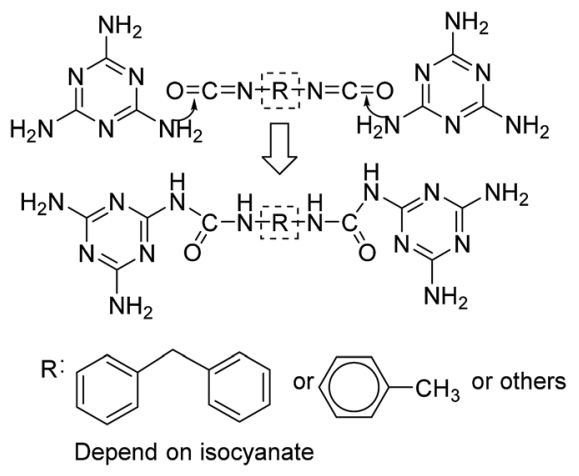

Scheme 5 Chemical reaction between isocyanate and melamine.

\subsection{Carbon-based additives}

Some carbon materials, such as expandable graphite (EG) and carbon nanotubes (CNTs), have been used in PU systems to inhibit the release of flames and smoke. ${ }^{156}$ During the initial process of combustion, the flame retardant, EG, rapidly expands and forms a loose and worm-like EG char layer that can hinder heat transmission to the inner matrix and reduce the release of decomposition fragments into the gas phase. Duquesne et $a .^{90}$ showed that the addition of EG in PU decreased the emission of toxic gases such as CO and HCN. According to the cone calorimeter test, these results show a total smoke release decrease to $40 \mathrm{wt} \%$ with $5 \mathrm{wt} \%$ loading of expandable graphite ${ }^{157}$ This is because EG creates a cross-linked carbonaceous char upon exposure to fire and small holes on the surface of the char contribute to the suppression of smoke. ${ }^{158}$ Feng and Qian combined DMMP and EG in rigid PU foam. With the addition of $22 \mathrm{wt} \% \mathrm{EG}$, the total smoke release decreased from 955 to $288 \mathrm{~m}^{2} \mathrm{~m}^{-2}$ and production of CO significantly decreased from 87.9 to $19.2 \mathrm{~kg} \mathrm{~kg}^{-1}$. Obviously, DMMP increases the smoke production of PU systems. EG can inhibit the smoke release of DMMP. ${ }^{94}$ The graphite oxide (GO) prepared from EG by the pressurized oxidation method was used in waterborne PU. With $1 \mathrm{wt} \%$ loading of GO, the total smoke release decreased from 650 to $470 \mathrm{~m}^{2} \mathrm{~m}^{-2}$ and the smoke factor decreased from 300 to $220 \mathrm{~kW} \mathrm{~m}^{-2}$. $^{159}$

This phenomenon can be attributed to the condensed phase flame retardancy, which leads to a compact and uniform char formation during combustion. ${ }^{160,161}$ Recent research efforts on introducing a small amount of CNTs into PU matrices to prepare high performance PU-CNTs composites has resulted in improved thermal stability. It was found that both CNTs and graphite have a minor impact on the decomposition process during the thermal degradation of PU. The addition of CNTs and graphite in PU prolong the release of combustion gas according to the Gram-Schmidt plots of TGA-FTIR. ${ }^{162}$ Pan et al. deposited $5.65 \mathrm{wt} \%$ titanate nanotubes via the Layer-By-Layer technique on flexible PU foam. A great reduction in the peak smoke production rate $(62.8 \%)$, total smoke release $(40.9 \%)$ and peak CO production $(63.5 \%)$ were achieved. The significant 
improvement in smoke suppression property could be attributed to the protective effect of the titanate nanotubes network structure, which provided an insulating barrier and an adsorption effect. ${ }^{28}$

\subsection{Miscellaneous additives}

In addition to the above mentioned compounds, other additives also have a smoke suppression effect in PU foam such as some sulphur-containing heterocyclic compounds and organic acids. Patent literature reports modification of PU foam into lowsmoke releasing foam. For PIR foams containing $10 \mathrm{wt} \%$ 2,3,4,5-tetrahydrofuran carboxylic acid, smoke production was reduced when tested according to SV-12 and ASTM D 2843-70 in a Rohm \& Hass XP2 smoke chamber test. ${ }^{163}$ The addition of 0.5$25 \mathrm{wt} \%$ an organosulphur compound resulted in the improvement of fire retardancy and reduction in smoke release. ${ }^{\mathbf{1 6 4}}$ Cyclodiphosph (V) azane of sulphaguanidine, 1,3-di-[N/-2pyrimidinylsulphanilamide]-2,2,2,4,4,4-hexachlorocycl additives with PU varnish. The presence of these additive diphosph (V) azanes was synthesized for use as a flame retardant results in the evolution of less toxic and less corrosive gases during fire compared to virgin PU. ${ }^{165}$ Addition of $11.6 \mathrm{pph}$ of zinc dibutyl dithiocarbamate $\mathrm{Zn}\left[\left(\mathrm{C}_{4} \mathrm{H}_{9}\right)_{2} \mathrm{NCS}_{2}\right]_{2}$ to a rigid $\mathrm{PU}$ recipe, resulted in about $38 \%$ smoke reduction. The addition of $20 \%$ zinc dimethyl dithiocarbamate resulted in $62 \%$ smoke reduction of rigid PU foam. ${ }^{\mathbf{1 6 6}}$ Doerge et al. introduced a series organic acids, fumaric acid, oxalic acid, maleic anhydride, citric acid, benzoic acid, malic acid and maleic acid, in PU foam. Results showed that most of the organic acids had smoke suppression effects and fumaric acid and maleic anhydride had excellent smoke suppression properties in PU foam. ${ }^{\mathbf{1 6 7}}$ Maleic acid, tartaric acid and malic acid as smoke suppressants are used in flexible PU foam. The presence of these organic acids achieved a delay in, or suppression of, the formulation of smoke and toxic gases. They not only reduced smoke formation, but also considerably delayed or reduced the evolution of toxic gases such as CO, $\mathrm{HCN}, \mathrm{NO}_{x}$ and organic nitrogen compounds. ${ }^{168}$

Additionally, some natural or synthetic hybrid compounds, such as vermiculite, LDH and MMT, have been employed in PU. In their investigations, Patra et al. deposited $4.5 \mathrm{wt} \%$ anionic vermiculite and cationic boehmite on PU foam. The total smoke release was reduced by $50 \%$. This was because the metal compound platelets can create a "nanobrick wall" structure that can effectively shield the foam from a heat source and decrease smoke production. ${ }^{169}$ Molybdenum-containing compounds have also been introduced into PU to suppress smoke release. Heptomolybdate $\left(\mathrm{Mo}_{7} \mathrm{O}_{24}{ }^{6-}\right)$ was intercalated in the interlayer space between MgAl-layered double hydroxides and then used in PU. The smoke density was reduced by about $32 \%$. This was due to the fact that $\mathrm{MoO}_{3}$, formed by the decomposition of MoMgAl LDHs, has an effective flame retardant and smoke suppression effect in PU. ${ }^{\mathbf{1 7 0}} \mathrm{LDH}$ has synergistic effects with intumescent flame retardants on improving the fire behaviour of rigid PU foams. The average smoke production rate (Av-SPR), average rate of smoke release (Av-RSR), average specific extinction area, total smoke release and $\mathrm{CO} / \mathrm{CO}_{2}$ weight ratio of a EG10/MPP10/LDH3.0/RPUF sample decrease about 26.9\%, $25.5 \%, 2.7 \%, 0.8 \%$ and $16.7 \%$, respectively, compared to that of pure RPUF. ${ }^{171}$ Lei et al. reported that, for PU-OMT composites, a decrease in CO release from $2.33 \mathrm{~kg} \mathrm{~kg}^{-1}$ to $0.33 \mathrm{~kg} \mathrm{~kg}^{-1}$ with 5 wt\% OMT loading. This OMT loading has a significant synergy with $6 \mathrm{wt} \% \mathrm{MMP}$ as there is a $53.4 \%$ decrease of CO production. During the combustion, OMT forms a glassy coat and, combined with the polyphosphoric acid from MMP decomposition, these protective barriers may insulate the underlying PU and induce smoke suppression. ${ }^{172}$

\section{Conclusions}

PU is one of the most versatile polymers, has great commercial importance and is widely used in both industry and in everyday life. However, PU is flammable and releases large amounts of smoke and toxic gasses during combustion, which increases the risk of this fire hazard. With increasing demand of flame retardant and low-smoke PU to meet environmental and fire safety requirements, studies on their thermal stability and smoke suppression strategies are important. This review summarized the study of related work performed in the last decade. It elaborated on the thermal decomposition of PU, smoke and toxicity of PU during combustion, factors influencing smoke production, smoke suppression methods and their mechanisms of action on PU. According to reports published in the literature, the thermal decomposition and combustion of PU is characterized by two to three degradation stages. Fire smoke of PU contains large amounts of toxic gases that easily cause poisoning and suffocation such as $\mathrm{CO}, \mathrm{HCN}$, $\mathrm{NO}_{x}$ and -NCO group containing compounds. Based on the analysis of PU thermal decomposition, the influencing factors of smoke production in combustion are the structure of the PU polymer chain (combustion conditions such as oxygen percentage), environmental temperatures and pressures present and the presence of flame retardants. Aromaticity in the main chains, and some stable structures such as PIR groups and carbodiimide groups, enable a decrease in the smoke production of PU. The flame retardant mechanism of various flame retardants can have an influence on smoke production. Additionally, the PU density and sample size can also influence smoke production.

Many studies have reported the use of smoke suppression additives and their mechanism for PU. They can be classified into five different types: (1) metal organic compounds (2) metal compounds (including metal oxides, metal salts, metal hydroxides and organic metal compounds), (3) melamine and its derivatives, (4) carbon materials and (5) other miscellaneous smoke suppressants. The mechanisms of smoke suppressants can be classified as either having a chemical or physical effect. Chemical interactions include Lewis acid effects, reductive coupling reactions and Friedel-Crafts reactions. Lewis acid sites in metal compounds that enable acceptance of an electron create a coordinate bond and enhances char-forming reactions. Some Lewis acids can also catalyse the toxic gas to non-toxic or solid compounds. These mechanisms can promote crosslinking and char formation 
and reduce smoke production. Physical interactions may play an important role too. Some hydrated compounds release water, which can dilute the concentration of toxic gases. Others additives hinder by interfering in the solid phase. Some additives enable a delay in the release of volatiles from the substrate and facilitate the formation of a compact char layer. Despite a lot of literature published in the area of PU thermal decomposition and its smoke suppression strategies, the understanding of its thermal decomposition and toxic gas production is incomplete. This is due to the complex compositions of PU (variety of available raw materials) and difficulties in the analysis of combustion gases. Additionally, strict regulations and material performance requirements motivate us to develop better smoke suppression strategies.

\section{Acknowledgements}

This work was funded by the China Scholarship Council.

\section{References}

1 J. G. Drohny, Handbook of Thermoplastic Elastomers, 2nd edn, 2014.

2 http://www.prnewswire.com/news-releases/global-poly urethanes-market-segmented-by-application-industry-andgeography-trends-and-forecasts-2015-2020-300155581.html.

3 Y. H. Lee, B. K. Kang, H. D. Kim, H. J. Yoo, J. S. Kim, J. H. Huh, Y. J. Jung and D. J. Lee, Macromol. Res., 2009, 17, 616-622.

4 M. Kotal, T. Kuila, S. K. Srivastava and A. K. Bhowmick, J. Appl. Polym. Sci., 2009, 114, 2691-2699.

5 M. C. Silva, J. A. Takahashi, D. Chaussy, M. N. Belgacem and G. G. Silva, J. Appl. Polym. Sci., 2010, 117, 3665-3672.

6 C. Y. H. Chao and J. H. Wang, Combust. Flame, 2001, 127, 2252-2264.

7 S. B. Nie, C. Peng, S. J. Yuan and M. X. Zhang, J. Therm. Anal. Calorim., 2013, 113, 865-871.

8 H. Harashina, Y. Tajima and T. Itoh, Polym. Degrad. Stab., 2006, 91, 1996-2002.

9 T. Kongkhlang, Y. Kousaka, T. Umemura, D. Nakaya, W. Thuamthong, Y. Pattamamongkolchai and S. Chirachanchai, Polymer, 2008, 49, 1676-1684.

10 V. M. Archodoulaki, S. Luftl and S. Seidler, Polym. Test., 2006, 25, 83-90.

11 L. A. Ferrari, M. G. Arado, L. Giannuzzi, G. Mastrantonio and M. A. Guatelli, Forensic Sci. Int., 2001, 121, 140-143.

12 R. Laskaris, Libr. J., 2012, 137, 80.

13 Q. J. Zhang, J. Zhan, K. Q. Zhou, H. D. Lu, W. R. Zeng, A. A. Stec, T. R. Hull, Y. Hu and Z. Gui, Polym. Degrad. Stab., 2015, 115, 38-44.

14 Fire Statistics United Kingdom 2007, Department for Communities and Local Government, London, Au-gust 2009, and preceding volumes.

15 S. V. Levchik and E. D. Weil, Polym. Int., 2005, 54, 11-35.

16 P. Carty and S. White, Polym. Degrad. Stab., 1994, 44, 9397.
17 Final Draft prEN 13501-1: Fire classification of construction products and building elements. Part 1: classification using test data from reaction to fire tests.

18 Standard, E. N. 13823, Reaction to fire tests for building products-Building products excluding floorings exposed to the thermal attack by a single burning item.

19 ISO 13571 2012. Life-threatening components of fire Guidelines for the estimation of time to com-promised tenability in fires.

20 Q. Zhang and Y. H. Chen, J. Polym. Res., 2011, 18, 293-303.

21 D. K. Chattopadhyay and D. C. Webster, Prog. Polym. Sci., 2009, 34, 1068-1133.

22 H. Singh and A. K. Jain, J. Appl. Polym. Sci., 2009, 111, 11151143.

23 E. D. Weil and S. V. Levchik, J. Fire Sci., 2004, 22, 183-210. 24 R. Jayakumar, S. Nanjundan and M. Prabaharan, React. Funct. Polym., 2006, 66, 299-314.

25 M. A. Garrido and R. Font, J. Anal. Appl. Pyrolysis, 2015, 113, 202-215.

26 R. H. Kramer, M. Zammarano, G. T. Linteris, U. W. Gedde and J. W. Gilman, Polym. Degrad. Stab., 2010, 95, 11151122.

27 M. Jimenez, N. Lesaffre, S. Bellayer, R. Dupretz, M. Vandenbossche, S. Duquesne and S. Bourbigot, RSC Adv., 2015, 5, 63853-63865.

28 H. F. Pan, W. Wang, Y. Pan, L. Song, Y. Hu and K. M. Liew, ACS Appl. Mater. Interfaces, 2015, 7, 101-111.

29 S. Gaan, S. Y. Liang, H. Mispreuve, H. Perler, R. Naescher and M. Neisius, Polym. Degrad. Stab., 2015, 113, 180188.

30 X. L. Chen, L. L. Huo, C. M. Jiao and S. X. Li, J. Anal. Appl. Pyrolysis, 2013, 100, 186-191.

31 L. Q. Zhang, M. Zhang, L. H. Hu and Y. H. Zhou, Ind. Crops Prod., 2014, 52, 380-388.

32 M. Zhang, Z. Y. Luo, J. W. Zhang, S. G. Chen and Y. H. Zhou, Polym. Degrad. Stab., 2015, 120, 427-434.

33 L. L. Jiao, H. H. Xiao, Q. S. Wang and J. H. Sun, Polym. Degrad. Stab., 2013, 98, 2687-2696.

34 X. R. Zheng, G. J. Wang and W. Xu, Polym. Degrad. Stab., 2014, 101, 32-39.

35 J. Jin, Q. X. Dong, Z. J. Shu, W. J. Wang and K. He, Procedia Eng., 2014, 71, 304-309.

36 L. P. Gao, G. Y. Zheng, Y. H. Zhou, L. H. Hu, G. D. Feng and M. Zhang, Polym. Degrad. Stab., 2014, 101, 92-101.

37 J. Paciorek-Sadowska, J. Porous Mater., 2012, 19, 161-171.

38 P. C. Chiu, Y. Ku, H. C. Wu, Y. L. Kuo and Y. H. Tseng, Fuel, 2014, 135, 146-152.

39 D. Ljubic, M. Srinivasan, R. Szoszkiewicz, I. Javni and Z. S. Petrovic, Eur. Polym. J., 2015, 70, 55-65.

40 S. M. Cakic, I. S. Ristic, I. Krakovsky, D. T. Stojiljkovic, P. Belsky and L. Kollova, Mater. Chem. Phys., 2014, 144, 31-40.

41 J. P. Lewicki, K. Pielichowski, P. T. De la Croix, B. Janowski, D. Todd and J. J. Liggat, Polym. Degrad. Stab., 2010, 95, 1099-1105.

42 J. Bozi, M. R. Mihalyi and M. Blazso, J. Anal. Appl. Pyrolysis, 2013, 101, 103-110. 
43 Z. Shah, F. Hasan, L. Krumholz, D. F. Aktas and A. A. Shah, Int. Biodeterior. Biodegrad., 2013, 79, 105.

44 M. Herrera, M. Wilhelm, G. Matuschek and A. Kettrup, J. Anal. Appl. Pyrolysis, 2001, 58, 173-188.

45 F. Gao, D. Price, G. J. Milnes, B. Eling, C. I. Lindsay and P. T. McGrail, J. Anal. Appl. Pyrolysis, 1997, 40-1, 217-231.

46 H. Wang, Q.-s. Wang, J.-j. He, Z.-l. Mao and J.-h. Sun, Procedia Eng., 2013, 52, 377-385.

47 G. Rein, C. Lautenberger, A. C. Fernandez-Pello, J. L. Torero and D. L. Urban, Combust. Flame, 2006, 146, 95-108.

48 B. H. Kim, K. Yoon and D. C. Moon, J. Anal. Appl. Pyrolysis, 2012, 98, 236-241.

49 D. Allan, J. H. Daly and J. J. Liggat, Polym. Degrad. Stab., 2014, 102, 170-179.

50 W. Xu, G. J. Wang and X. R. Zheng, Polym. Degrad. Stab., 2015, 111, 142-150.

51 M.-C. H. Han-hsi Liang, Construct. Build. Mater., 2007, 21, 1254-1261.

52 F. M. Esposito and Y. Alarie, J. Fire Sci., 1988, 6, 195-242.

53 Naval Engineering Standard 713, Issue 3, Determination of the toxicity index of the products of combustion from small specimens of materials, March 1985.

54 C. T. Lee, H. G. Poovey, R. J. Rando and G. W. Hoyle, Toxicol. Appl. Pharmacol., 2007, 224, 19-28.

55 C. T. Lee, J. Ylostalo, M. Friedman and G. W. Hoyle, Toxicol. Appl. Pharmacol., 2005, 205, 53-64.

56 J. C. Varone, Fire Eng., 2006, 159, 61-70.

57 S. V. Levchik and E. D. Weill, Polym. Int., 2004, 53, 15851610.

58 J. P. David Purser, presented in part at the In: Fire safety science - proceedings of the ninth international symposium, London, 21-26 September, 2008.

59 W. D. Woolley, P. J. Fardell and I. G. Buckland, Fire Research Notes, 1975, 1039, 1-16.

60 G. E. Hartyell, J. Cell. Plast., 1992, 28, 25.

61 Y. J. Chen, Z. P. Liu, P. G. Dai and L. Liu, Bulg. Chem. Commun., 2014, 46, 882-886.

62 E. Matthew, G. Warden and J. Dedman, Am. J. Physiol.: Lung Cell. Mol. Physiol., 2001, 280, L716-L723.

63 Z. D. Han, A. Fina, G. Malucelli and G. Camino, Prog. Org. Coat., 2010, 69, 475-480.

64 C. M. Jiao, X. L. Zhao, W. K. Song and X. L. Chen, J. Therm. Anal. Calorim., 2015, 120, 1173-1181.

65 A. A. Stec and T. R. Hull, Energ. Buildings, 2011, 43, 498-506. 66 ISO 13344:2004, Estimation of the Lethal Toxic Potency of Fire Effluents, 2004.

67 B. C. Levin, E. Braun, M. Paabo, R. H. Harris and M. Navarro, Reduction of hydrogen cyanide concentrations and acute inhalation toxicity from flexible polyurethane foam combustion products by the addition of copper compounds, Master Degree, National Institute of Standards and Technology, 1992.

68 H. S. Han and P. K. Bhowmik, Prog. Polym. Sci., 1997, 22, 1431-1502.

69 T. J. Dingemans, E. Mendes, J. J. Hinkley, E. S. Weiser and T. L. StClair, Macromolecules, 2008, 41, 2474-2483.
70 P. Patel, T. R. Hull, R. E. Lyon, S. I. Stoliarov, R. N. Walters, S. Crowley and N. Safronava, Polym. Degrad. Stab., 2011, 96, 12-22.

71 P. Patel, T. R. Hull, R. W. McCabe, D. Flath, J. Grasmeder and M. Percy, Polym. Degrad. Stab., 2010, 95, 709-718.

72 I. Butnaru, D. Serbezeanu, M. Bruma, I. Sava, S. Gaan and G. Fortunato, High Perform. Polym., 2015, 27, 616-624.

73 D. Serbezeanu, I. Butnaru, C.-D. Varganici, M. Bruma, G. Fortunato and S. Gaan, RSC Adv., 2016, 6, 38371-38379.

74 M. Kuranska, A. Prociak, M. Kirpluks and U. Cabulis, Ind. Crops Prod., 2015, 74, 849-857.

75 S. A. Omer, S. B. Riffat and G. Qiu, Build. Serv. Eng. Tech., 2007, 28, 275-293.

$76 \mathrm{~J}$. Troitzsch, International plastics flammability handbook. Principles - regulations - testing and approval, Munich, 1990.

77 P. R. Nair, C. P. R. Nair and D. J. Francis, J. Appl. Polym. Sci., 1999, 71, 1731-1738.

78 K. C. Frisch, K. J. Patel and R. D. Marsh, J. Cell. Plast., 1970, 6, 203-214.

79 P. G. Pape, J. E. Sanger and R. C. Nametz, SPE J., 1968, 24, 42-47.

80 E. Dominguez-Rosado, J. J. Liggat, C. E. Snape, B. Eling and J. Pichtel, Polym. Degrad. Stab., 2002, 78, 1-5.

81 J. Wang, D. Liu, G. Wang, W. Han, Q. Zhang, X. Wang and Y. Wang, Polym. Mater.: Sci. Eng., 2013, 29, 64-67.

82 J. Xu and T. Y. Fang, 9th Asia-Oceania Symposium on Fire Science and Technology, 2013, 62, pp. 837-843.

83 L. B. Valencia, T. Rogaume, E. Guillaume, G. Rein and J. L. Torero, Fire Saf. J., 2009, 44, 933-940.

84 Y. P. Cheng, M. J. Zhang, L. Chen and J. W. Ji, Prog. Saf. Sci. Technol., 2002, 3, 1286-1291.

85 W. K. Chow, Polym. Test., 2004, 23, 973-977.

86 P. Blomqvist, T. Hertzberg, H. Tuovinen, K. Arrhenius and L. Rosell, Fire Mater., 2007, 31, 495-521.

87 P. Blomqvist, Emissions from Fires Consequences for Human Safety and the Environment, Ph. D degree, Department of Fire Safety Engineering Lund Institute of Technology Lund University, 2005.

88 G. Camino, S. Duquesne, R. Delobel, B. Eling, C. Lindsay and T. Roels, ACS Symp. Ser., 2001, 797, 90-109.

89 S. Levchik, Non-Halogenated Flame Retardant Handbook, 2014.

90 S. Duquesne, M. Le Bras, S. Bourbigot, R. Delobel, F. Poutch, G. Camino, B. Eling, C. Lindsay and T. Roels, J. Fire Sci., 2000, 18, 456-482.

91 A. Granzow, Acc. Chem. Res., 1978, 11, 177-183.

92 B. Youssef, B. Mortaigne, M. Soulard and J. M. Saiter, J. Therm. Anal. Calorim., 2007, 90, 489-494.

93 M. Checchin, C. Cecchini, B. Cellarosi and F. O. Sam, Polym. Degrad. Stab., 1999, 64, 573-576.

94 F. F. Feng and L. J. Qian, Polym. Compos., 2014, 35, 301-309. 95 V. Babrauskas, B. C. Levin, R. G. Gann, M. Paabo, R. H. Harris Jr, R. D. Peacock and S. Yusa, Master, 1991.

96 N. Najafi-Mohajeri, C. Jayakody and G. L. Nelson, ACS Symp. Ser., 2001, 797, 79-89. 
97 M. J. Chen, Y. J. Xu, W. H. Rao, J. Q. Huang, X. L. Wang, L. Chen and Y. Z. Wang, Ind. Eng. Chem. Res., 2014, 53, 8773-8783.

98 M. Hurd, D. Torvi, E. Weckman and E. Enninful, Proceedings of Fire and Materials conference, 2007.

99 J. Urbas, Fire Mater., 2005, 29, 1-13.

100 D. T. Melinda Hurd, E. Weckman and E. Enninful, Presented in part at the Proceedings of the International Fire and Materials Conference, 2007.

101 J. Lefebvre, B. Bastin, M. Le Bras, S. Duquesne, R. Paleja and R. Delobel, Polym. Degrad. Stab., 2005, 88, 28-34.

102 W. Aufmuth, S. V. Levchik, G. F. Levchik and M. Klatt, Fire Mater., 1999, 23, 1-6.

103 E. D. Weil and N. G. Patel, Polym. Degrad. Stab., 2003, 82, 291-296.

104 J. Z. Xu, C. H. Liu, H. Q. Qu, H. Y. Ma, Y. H. Jiao and J. X. Xie, Polym. Degrad. Stab., 2013, 98, 1506-1514.

105 F. H. Wang, W. Jiang, Y. Fang and C. W. Cheng, Chem. Eng. J., 2015, 259, 827-836.

106 G. W. Yeager, D. M. White and J. E. Pickett, US4757107 A, 1988.

107 G. Moroi and C. Ciobanu, Thermochim. Acta, 2002, 385, 153-162.

108 R. Jayakumar, Y. S. Lee and S. Nanjundan, React. Funct. Polym., 2003, 55, 267-276.

109 B. C. Levin, Toxicology, 1996, 115, 89-106.

110 H. K. Moores, D. T. Janigan and R. P. Hajela, Toxicol. Pathol., 1993, 21, 521-527.

111 B. C. Levin, Drug Chem. Toxicol., 1997, 20, 271-280.

112 R. P. Lattimer and W. J. Kroenke, J. Appl. Polym. Sci., 1981, 26, 1191-1210.

113 S. Bodrero, presented in part at the National Academies Press, Stamford, 1992.

114 X. L. Chen, Y. F. Jiang and C. M. Jiao, J. Hazard. Mater., 2014, 266, 114-121.

115 M. Lin, B. Li, Q. F. Li, S. Li and S. Q. Zhang, J. Appl. Polym. Sci., 2011, 121, 1951-1960.

116 E. Gallo, B. Schartel, D. Acierno and P. Russo, Eur. Polym. J., 2011, 47, 1390-1401.

117 S. R. Dhakate, R. B. Mathur and O. P. Bahl, Carbon, 1997, 35, 1753-1756.

118 P. Carty, J. R. Creighton and S. White, J. Therm. Anal. Calorim., 2001, 63, 679-687.

119 P. Carty and S. White, Polym. Degrad. Stab., 2002, 75, 173184.

120 O. Terakado, H. Yanase and M. Hirasawa, J. Anal. Appl. Pyrolysis, 2014, 108, 130-135.

121 T. Suebsaeng, C. A. Wilkie, J. Carter, V. T. Burger and C. E. Brown, J. Polym. Sci., Polym. Lett. Ed., 1984, 22, 625634.

122 C. Q. Wang, H. N. Lv, J. Sun and Z. S. Cai, Polym. Eng. Sci., 2014, 54, 2497-2507.

123 X. Liu, Y. Zhou, J. W. Hao and J. X. Du, J. Appl. Polym. Sci., 2015, 132.

124 F. Yang and G. L. Nelson, Presented in part at the Proceedings of the 22th Annual BCC Conference on Flame Retardancy, 2011.
125 F. Yang and G. L. Nelson, ACS Symp. Ser., 2012, 1118, 139149.

126 Y. Q. Shi, B. Yu, K. Q. Zhou, R. K. K. Yuen, Z. Gui, Y. Hu and S. H. Jiang, J. Hazard. Mater., 2015, 293, 87-96.

127 J. B. A. Mitchell, Combust. Flame, 1991, 86, 179-184.

128 K. Gonsalves, Z. R. Lin and M. D. Rausch, J. Am. Chem. Soc., 1984, 106, 3862-3863.

129 K. E. Gonsalves and M. D. Rausch, J. Polym. Sci., Part A: Polym. Chem., 1986, 24, 1599-1607.

130 B. S. Cho, J. S. Kim, S. C. Kang and S. T. Noh, Thermochim. Acta, 2013, 556, 18-22.

131 P. K. K. Kishore and K. Jyanar, J. Polym. Sci., Part A: Polym. Chem., 1991, 29, 16.

132 C. Jayakody, G. L. Nelson, U. Sorathia and S. Lewandowski, J. Fire Sci., 1998, 16, 351-382.

133 N. Najafi-Mohajeri, G. L. Nelson and R. Benrashid, J. Appl. Polym. Sci., 2000, 76, 1847-1856.

134 W. Ye, L. Du and X. Tian, Int. Polym. Process., 2014, 29, 191196.

135 L. Liu, X. L. Chen and C. M. Jiao, J. Therm. Anal. Calorim., 2015, 122, 437-447.

136 N. Khamma, D. Krisiri, P. Tachaprasertporn and N. Chantarasiri, J. Appl. Polym. Sci., 2008, 108, 245-255.

137 A. F. Grand and C. A. Wilkie, Fire retardancy of polymeric materials, Marcel Dekker, New York, 2000, pp. 245-283.

138 A. M. Lyons, E. M. Pearce and A. M. Mujsce, J. Polym. Sci., Part A: Polym. Chem., 1990, 28, 245-259.

139 X. L. Chen, W. K. Song, J. B. Liu, C. M. Jiao and Y. Qian, J. Therm. Anal. Calorim., 2015, 120, 1819-1826.

140 Z. Yang, J. Cai, C. G. Zhou, D. Zhou, B. F. Chen, H. Yang and R. S. Cheng, J. Appl. Polym. Sci., 2010, 118, 2634-2641.

141 S. V. Levchik and E. D. Weil, Polym. Adv. Technol., 2005, 16, 707-716.

142 W. J. Wang, K. He, Q. X. Dong, N. Zhu, Y. Fan, F. Wang, Y. B. Xia, H. F. Li, J. Wang, Z. Yuan, E. P. Wang, Z. F. Lai, T. Kong, X. Wang, H. W. Ma and M. S. Yang, J. Appl. Polym. Sci., 2014, 131, 39936.

143 Y. L. Liu, J. Y. He and R. J. Yang, Ind. Eng. Chem. Res., 2015, 54, 5876-5884.

144 T. Englmann, A. Luks, O. Töpfer and R. Sauerwein, Wire J. Int., 2013, 46, 50-56.

145 M. Thirumal, N. K. Singha, D. Khastgir, B. S. Manjunath and Y. P. Naik, J. Appl. Polym. Sci., 2010, 116, 2260-2268.

146 Y. Pan, J. Zhan, H. F. Pan, W. Wang, H. Ge, L. Song and Y. Hu, RSC Adv. , 2015, 5, 67878-67885.

147 H. Horacek and R. Grabner, Polym. Degrad. Stab., 1996, 54, 205-215.

148 B. V. Lotsch and W. Schnick, Chem.-Eur. J., 2007, 13, 49564968.

149 A. Konig, U. Fehrenbacher, E. Kroke and T. Hirth, J. Fire Sci., 2009, 27, 187-211.

150 M. Modesti and A. Lorenzetti, Polym. Degrad. Stab., 2002, 78, 341-347.

151 M. Thirumal, D. Khastgir, G. B. Nando, Y. P. Naik and N. K. Singha, Polym. Degrad. Stab., 2010, 95, 1138-1145.

152 G. Oertel, Polyurethane Handbook, Hansa, Munich, 1994. 
153 R. Bashirzadeh and A. Gharehbaghi, J. Cell. Plast., 2010, 46, 129-158.

154 D. M. Xu, F. Ding, J. W. Hao and J. X. Du, Chem. J. Chin. Univ., 2013, 34, 2674-2680.

155 D. Price, Y. Liu, G. J. Milnes, R. Hull, B. K. Kandola and A. R. Horrocks, Fire Mater., 2002, 26, 201-206.

156 Y. Xu, M. Chen, X. Ning, X. L. Chen, Z. D. Sun, Y. H. Ma, J. Yu, Z. B. Zhang, X. J. Bo, L. Yang and Z. N. Chen, J. Therm. Anal. Calorim., 2014, 115, 689-695.

157 X. Hu, D. Wang and S. Wang, Int. J. Min. Sci. Technol., 2013, 23, 13-20.

158 U. Braun, B. Schartel, M. A. Fichera and C. Jager, Polym. Degrad. Stab., 2007, 92, 1528-1545.

159 J. Hu and F. Zhang, J. Therm. Anal. Calorim., 2014, 118, 1561-1568.

160 M. Thirumal, D. Khastgir, N. K. Singha, B. S. Manjunath and Y. P. Naik, J. Appl. Polym. Sci., 2008, 110, 2586-2594.

161 L. Ye, X. Y. Meng, X. Ji, Z. M. Li and J. H. Tang, Polym. Degrad. Stab., 2009, 94, 971-979.

162 E. Ciecierska, M. Jurczyk-Kowalska, P. Bazarnik, M. Kowalski, S. Krauze and M. Lewandowska, J. Therm. Anal. Calorim., 2016, 213, 283-291.
163 W. J. Kauffman and E. J. Quinn, U.S. Pat., 4,069,173, 1978.

164 D. C. Wysocki, Low smoke-output polyurethane and polyisocyanurate foams, 1976.

165 H. A. El-Wahab, M. A. El-Fattah, N. A. El-Khalik and C. M. Sharaby, Prog. Org. Coat., 2012, 74, 615-621.

166 S. R. Sandler and J. D. Miano, Smoke suppressed rigid polyurethane foam, 1982.

167 H. P. Doerge and M. Wismer, Urethane foams with reduced smoke levels, 1972.

168 D. A. Smith, S. J. Grayson and J. Hume, US4444914 A, 1984.

169 D. Patra, P. Vangal, A. A. Cain, C. Cho, O. Regev and J. C. Grunlan, ACS Appl. Mater. Interfaces, 2014, 6, 1690316908.

170 W. Z. Xu, S. Q. Wang, L. Liu and Y. Hu, Polym. Adv. Technol., 2016, 27, 250-257.

171 L. Gao, G. Zheng, Y. Zhou, L. Hu, G. Feng and Y. Xie, Ind. Crops Prod., 2013, 50, 638-647.

172 L. Song, Y. Hu, Y. Tang, R. Zhang, Z. Y. Chen and W. C. Fan, Polym. Degrad. Stab., 2005, 87, 111-116. 